\title{
Alport syndrome, mental retardation, midface hypoplasia, and elliptocytosis: a new X linked contiguous gene deletion syndrome?
}

\author{
Jon J Jonsson, Alessandra Renieri, Patrick G Gallagher, Clifford E Kashtan, \\ Elizabeth M Cherniske, Mirella Bruttini, Monica Piccini, Francesca Vitelli, \\ Andrea Ballabio, Barbara R Pober
}

\section{Department of \\ Genetics, Yale \\ University School of \\ Medicine, PO Box \\ 208005, New Haven, \\ Connecticut \\ 06520-8005, USA \\ J J Jonsson ${ }^{\star}$ \\ E M Cherniske \\ B R Pober}

\section{Medical Genetics, Department of \\ Molecular Biology, \\ Policlinico Le Scotte, \\ Siena, Italy \\ A Renieri \\ M Bruttini \\ M Piccini \\ A Ballabio \\ F Vitelli}

Department of

Pediatrics, Yale

University School of

Medicine, New Haven, Connecticut, USA

P G Gallagher

Department of Pediatrics, University of Minnesota, Minneapolis, Minnesota, USA

C E Kashtan

Correspondence to: Dr Pober.

^Present address: Department of Clinical Biochemistry, Landspitalinn Reykjavik, Iceland.

Received 28 May 1997 Revised version accepted for publication 14 October 1997

\begin{abstract}
We describe a family with four members, a mother, two sons, and a daughter, who show clinical features consistent with $X$ linked Alport syndrome. The two males presented with additional features including mental retardation, dysmorphic facies with marked midface hypoplasia, and elliptocytosis. The elliptocytosis was not associated with any detectable abnormalities in red cell membrane proteins; red cell membrane stability and rigidity was normal on ektacytometry.

Molecular characterisation suggests a submicroscopic $\mathbf{X}$ chromosome deletion encompassing the entire COL4A5 gene. We propose that the additional abnormalities found in the affected males of this family are attributable to deletion or disruption of $X$ linked recessive genes adjacent to the COL4A5 gene and that this constellation of findings may represent a new $X$ linked contiguous gene deletion syndrome.

(F Med Genet 1998;35:273-278)
\end{abstract}

Keywords: Alport syndrome; mental retardation; midface hypoplasia; elliptocytosis

Alport syndrome is a genetically heterogeneous disorder characterised by renal abnormalities, sensorineural hearing loss, and eye abnormalities. ${ }^{1}$ Alport syndrome is caused by mutations in several different genes all encoding particular isoforms of type IV collagen, a major component of basement membranes. The $\mathrm{X}$ linked dominant form of this disorder (OMIM 30105) is caused by mutations in COL4A5, a gene which maps to Xq22 and codes for the $\alpha 5$ (IV) chain of type IV collagen. ${ }^{2}$ An autosomal recessive form of Alport syndrome (OMIM 203780) arising from mutations in the COL4A3 and COL4A4 genes has been characterised. ${ }^{3}$ Segregation analysis in some families suggests an autosomal dominant form as well. ${ }^{4}$ Mutations in the COL4A5 gene associated with Alport syndrome are very heterogeneous ${ }^{56}$ and deletions are present in approximately $10 \%$ of patients. ${ }^{7}$ In rare instances, patients with Alport syndrome have additional features not generally associated with the condition. Best characterised is diffuse leiomyomatosis involving the oesophagus, tracheobronchial tree, and uterus (OMIM 308940). This condition is associated with deletions involving the COL4A5 gene extending into the first two exons of the neighbouring COL4A6 gene; deletions extending beyond exon 2 do not produce leiomyomas. ${ }^{9-12}$ Features not directly connected with abnormalities in type IV collagen have also been described; these include specific haematological abnormalities such as macrothrombocytopenia (OMIM 153650) ${ }^{13}$ either alone or in conjunction with leucocyte inclusions (OMIM 153640) ${ }^{14}$ and May-Hegglin anomaly. ${ }^{15} \mathrm{~A}$ family with $\mathrm{X}$ linked nephritis and sensorineural hearing loss is the subject of a recent report in which affected male relatives also have macrocephaly and mental retardation. ${ }^{16}$

This report describes a family with four members, a mother, two sons, and a daughter, who all have clinical features consistent with $\mathrm{X}$ linked Alport syndrome. The two males have additional features including mental retardation, dysmorphic facies with marked midface hypoplasia, and elliptocytosis. This phenotype was associated with a submicroscopic deletion on the $\mathrm{X}$ chromosome involving the entire COL4A5 gene in all four family members. We propose that the additional abnormalities in affected males of this family are caused by deletion or disruption of $\mathrm{X}$ linked recessive genes adjacent to the COL4A5 gene and that this constellation of findings probably represents a new $\mathrm{X}$ linked contiguous gene deletion syndrome.

\section{Methods}

\section{IMMUNOHISTOCHEMISTRY}

Epidermal basement membrane expression of the $\alpha 1$ and $\alpha 5$ chains of type IV collagen was studied using monoclonal antibodies (Mab). Rat Mab 102 is directed against the NC1 domain of the $\alpha 1$ (IV) chain. ${ }^{17}$ Mouse Mab A7 is directed against the $\alpha 5$ (IV) NC1 domain. ${ }^{18}$ Fluorescein isothiocyanate conjugated goat anti-rat or anti-mouse IgG preparations (PelFreeze, Rogers, Arkansas) were preabsorbed with normal human serum and used as secondary antibodies.

A skin biopsy specimen ( $3 \mathrm{~mm}$ ) was snap frozen in liquid nitrogen and stored at $-70^{\circ} \mathrm{C}$. Cryostat sections were cut using a Lipshaw cryostat maintained at constant temperature $\left(25^{\circ} \mathrm{C}\right)$ and humidity $(30 \%)$ then fixed for 10 minutes in acetone (for non-denatured sections) or ethanol (for denatured sections). Ethanol fixed sections were denatured by exposure to $0.1 \mathrm{~mol} / 1$ glycine, $6 \mathrm{~mol} / \mathrm{l}$ urea $(\mathrm{pH}$ 3.5) for one hour at $4^{\circ} \mathrm{C}$ as previously 
I

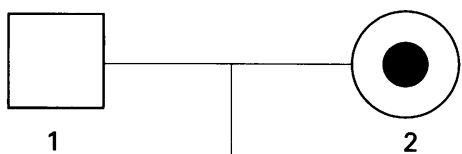

39 years old No medical problems Normal RBC morphology

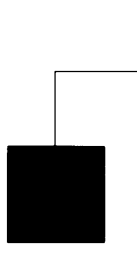<smiles>CCCC</smiles>
1

7 years old Haematuria

Mixed hearing loss

Mental retardation

Midface hypoplasia

Digital anomalies

Elliptocytosis Myopia

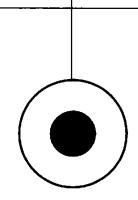

2

5 years old

Microhaematuria

Normal RBC

morphology
38 years old

Haematuria

Unilateral sensorineural

hearing loss

Normal RBC morphology

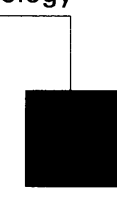

3

3 years old

Microhaematuria

Sensorineural hearing loss

Mental retardation

Midface hypoplasia

Digital anomalies

Elliptocytosis
Figure 1 Pedigree of family. Age and clinical features of each subject are indicated.

described. ${ }^{19}$ Mab 102 was used on nondenatured sections, while Mab A7 was applied to denatured sections. ${ }^{20}$ Sections were examined using an epifluorescence microscope with appropriate filters (Zeiss, Oberkochen, Germany).

MOLECULAR GENETIC ANALYSIS

Genomic DNA was isolated from peripheral blood using Puregene kit (Gentra Systems, Minneapolis, Minnesota). PCR analysis was performed as described by Renieri et al. ${ }^{5}$ Southern blot analysis was performed essentially as previously described. ${ }^{8}$ Briefly, $10 \mu \mathrm{g}$ of genomic DNA was digested with EcoRI restriction enzyme. Genomic DNA fragments were separated by electrophoresis in a $0.8 \%$ agarose gel and transferred to a nylon membrane (Hybond-N+). The membrane was hybridised to an isotopic labelled cDNA probe, ${ }^{21}$ washed, and exposed to X-OMAT film (Kodak) overnight.

\section{MECHANICAL STABILITY OF ERYTHROCYTE}

\section{MEMBRANES}

Resealed red cell membranes were prepared by a procedure adapted from Johnson. ${ }^{22}$ For mechanical stability measurements, $150 \mu$ of the membrane suspension was mixed with 3.5 $\mathrm{ml}$ dextran solution (290 mOsmol, $\mathrm{pH} 7.4$, and viscosity 95 centipoise) and subjected continuously to $750 \mathrm{dyn} / \mathrm{cm}^{2}$ in an ektacytometer ${ }^{23}$ (testing kindly performed by Dr Narla Mohandes, Lawrence Berkeley Laboratory, Berkeley, CA). Under this stress, the membranes progressively fragment, generating undeformable spheres. This process is detected as a time dependent decrease in the deformability index (DI). The rate of decline of DI is a measure of membrane mechanical stability. Well established values for the rate of decline of DI are available for erythrocytes from patients with mild, moderate, and severe elliptocytosis. ${ }^{23}$
STUDIES OF ERYTHROCYTE MEMBRANE PROTEINS Erythrocyte membranes were prepared from peripheral blood as described previously. ${ }^{24}$ Membrane proteins were separated by one dimensional SDS-PAGE in 3.5-17\% gradient polyacrylamide gels and stained with Coomassie blue. Band ratios were obtained by scanning the stained gels using the Personal Densitometer Laser Scanner (Molecular Dynamics, Sunnyvale, CA) and then calculating the total amount of protein/band using Imagequant software (Molecular Dynamics).

\section{Case reports (fig 1)}

PROBAND (II.1)

The male proband was born by forceps assisted vaginal delivery following a 41 week, uncomplicated pregnancy to a 30 year old, gravida 1 para 0 mother. The maternal ethnic background was English and the paternal background was German and Eastern European. Labour was induced for post-term and intrauterine growth retardation. Birth weight and length were on
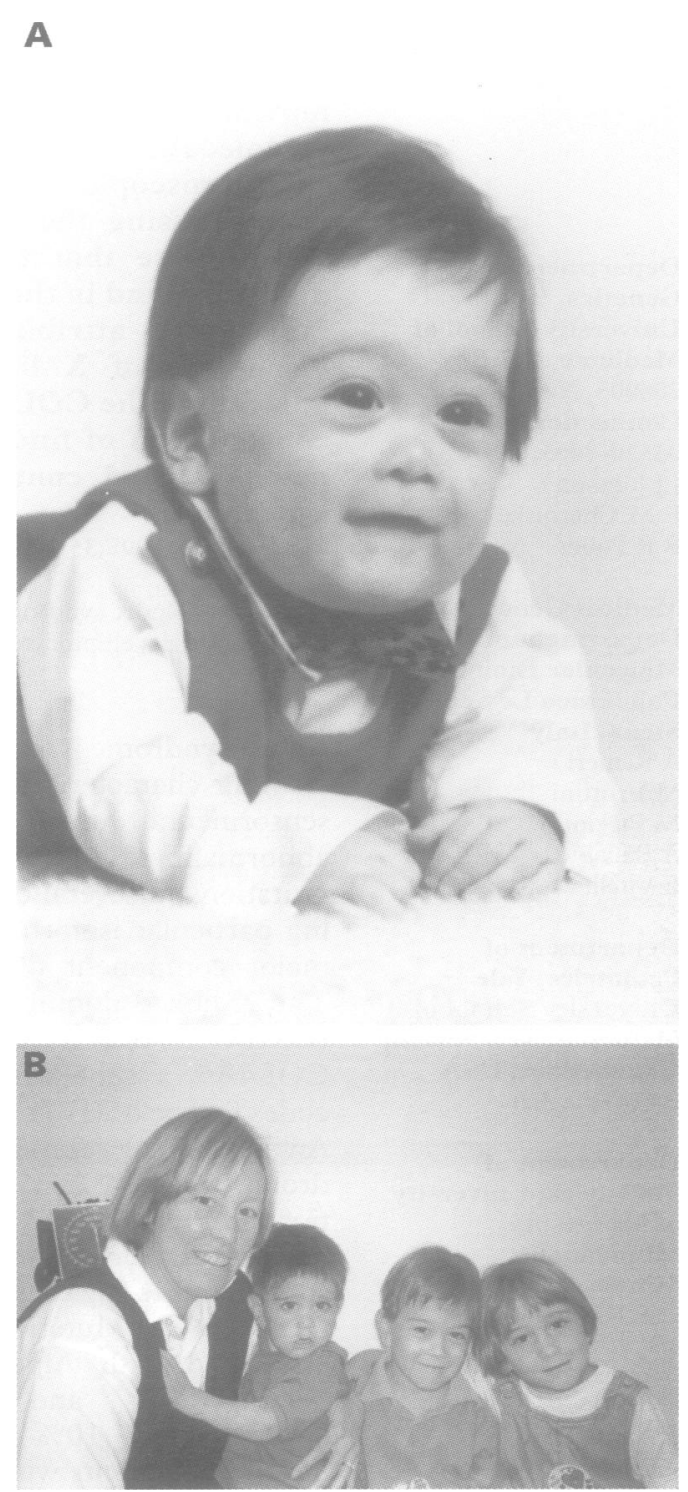

Figure 2 Photographs of affected family members. (A) Proband at 6 months of age. Note marked midface hypoplasia. (B) Note similar abnormal facial features in the proband at 7 years and his younger brother at 3 years (in mother's lap). Note absence of midface hypoplasia in the mother and daughter. 


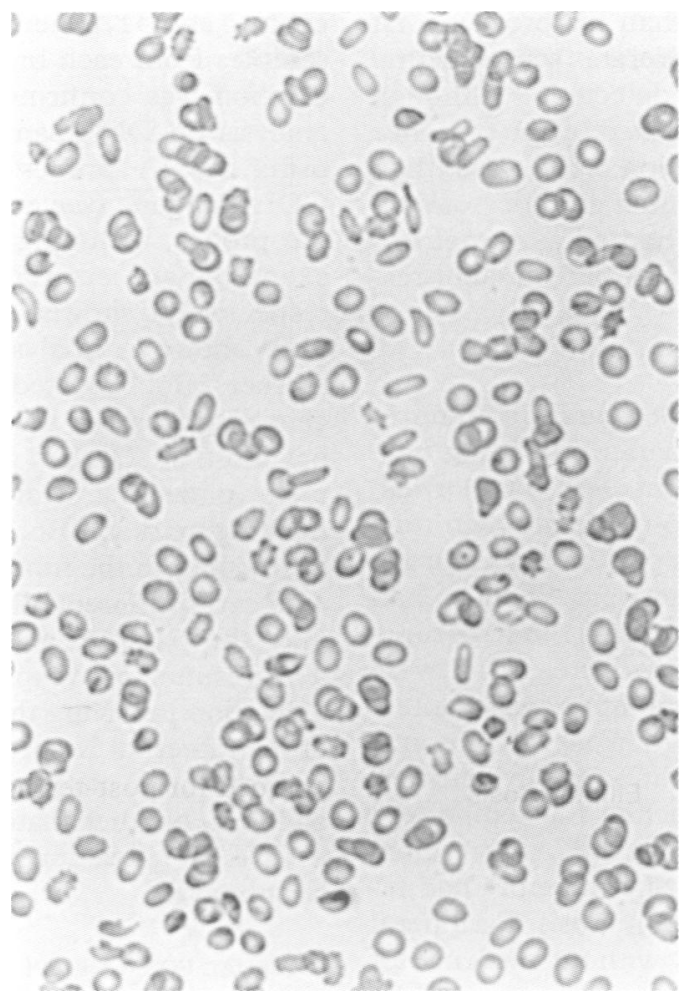

Figure 3 Mild to moderate elliptocytosis on Wright stained blood smear from the proband.

the 10th centile and head circumference on the 75 th centile. Apgar scores were 8 and 9 at one and five minutes, respectively. The neonatal period was complicated by transient hyperbilirubinaemia (highest level $31 \mu \mathrm{mol} / \mathrm{l}$ ), feeding difficulties, and neurological abnormalities including poor head control and increased tone in the lower extremities. Facial dysmorphology was noted in the immediate neonatal period. Features included marked midface hypoplasia, a flat nasal bridge, hypotelorism, and epicanthic folds (fig $2 \mathrm{~A}$ ). Inner canthal and interpupillary distances were below the 3rd centile. The proband also had anteverted nares, a high
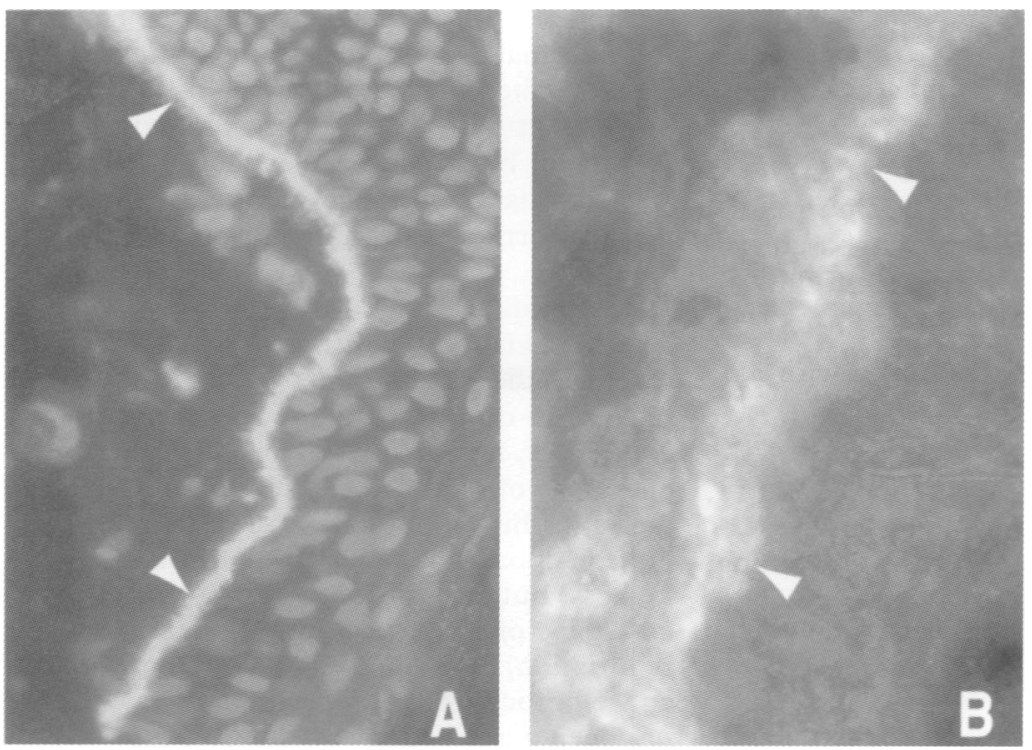

Figure 4 Skin biopsy of the proband obtained at 5 years 9 months of age. (A) Epidermal basement membrane (EBM) in control skin from a normal subject showing intense staining for a5 chain of type IV collagen (arrowheads). (B) No specific EBM staining for a5(IV) chain was detected in skin biopsy from the proband (arrowheads). EBM in both specimens stained intensely positive for a1 (IV) chain (data not shown). arched palate, a thin upper lip, and a small chin. Minor digital anomalies were noted including persistent fetal pads, increased space between the index and middle fingers as well as the first and second toes, in conjunction with second toe clinodactyly. The patient was described at 3 months of age as having global hypotonia and head lag; subsequent body habitus reflected mild hypotonia and joint hypermobility. Abdominal musculature was lax with rectus diastasis and umbilical hernia. In addition, an inguinal hernia developed and was repaired at 6 years of age. The patient had a high degree of anisometropia including marked unilateral myopia requiring corrective lenses.

CT scan of the head at 12 weeks of age showed bihemispheric atrophy and densities in the right frontal and caudate lobes suggestive of perinatal stroke. MRI of the head at 3 years of age showed small areas of signal drop in the basal ganglia consistent with previous infarction. Audiological evaluation at 6 years of age showed mild to moderate hearing loss, in part attributed to middle ear pathology. The proband's overall development was delayed. He sat at 8 months, crawled at 1 year, and walked at 22 months of age. Formal speech evaluation was done at 5 years 9 months of age. Receptive speech was at the 2-3 year level and expressive speech at the 1 year level.

Linear growth followed the 5th centile, weight followed the 50th centile, and head circumference the 75 th centile. Skeletal surveys at 4 months and at 3 years of age were unremarkable. At $2 \frac{1}{2}$ years of age, macroscopic haematuria was noted which resolved over a period of two months. Renal and abdominal ultrasound examinations at that time were within normal limits. The patient continued to have episodic macroscopic and persistent microscopic haematuria. No gastrointestinal or respiratory symptoms had been reported. Blood pressure was normal.

Routine biochemical tests including serum urea and creatinine were normal. The proband had an extensive, unremarkable biochemical genetics evaluation including plasma lactate, pyruvate, phytanic acid, very long chain fatty acids, and plasma and urine amino and organic acid analyses. Tests for storage disease were negative as well. No FRAXA trinucleotide expansion was present on Southern analysis.

Haemoglobin was consistently in the low normal range and mild to moderate elliptocytosis was present on blood smear (fig 3). However, there was no evidence of haemolysis on peripheral smear and the reticulocyte count was normal.

Chromosome preparations from peripheral blood lymphocytes stained with Giemsa, GTG, QFQ, and CA3/Mg banding showed a $46, X Y$ karyotype. High resolution prometaphase study focused on Xq22 showed no abnormality.

YOUNGER BROTHER (II.3)

The proband's younger brother presented with virtually the same features as his older brother (fig 2). His head circumference was on the 25th centile. He had developmental delay but to a 


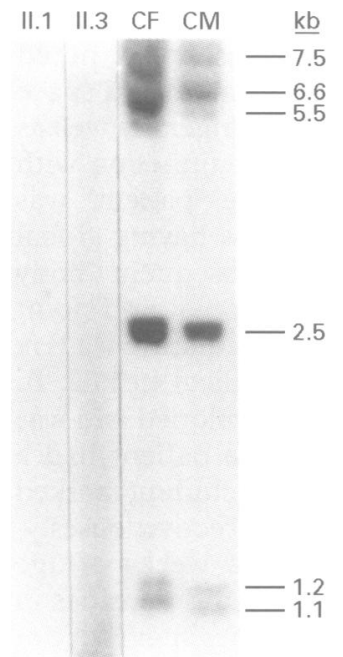

Figure 5 Southern blot analysis using one (HE6) of the six probes ( $7 Z 4{ }^{26}$ PF17, HE10, HE6, PF6, and $P F 7^{21}$ ) covering the entire COL $4 A 5$ gene. Genomic DNA from the proband, II.1 (lane 1), his affected brother, II. 3 (lane 2), and two controls lane 3, normal female, and lane 4, normal male). DNA was digested with EcoRI restriction enzyme and probed by HE6 which spans exons 38 to 50 of the COL4A5 gene. No hybridisation signal was detected in the genomic DNA of the proband or his affected brother. Numbers on right indicate size of fragments in $k b$. somewhat lesser degree than his brother's. At 15 months of age, moderate sensorineural hearing loss was detected although interpretation was complicated by the presence of a middle ear effusion. He also had microhaematuria and distinct elliptocytosis on blood smear. At 3 years he had asymmetrical astigmatism. He had no gastrointestinal or respiratory symptoms.

MOTHER (I.2)

The mother at the age of 38 years had an unremarkable physical examination including normal blood pressure. Her intellect was normal. She had unilateral mild to moderate high tone sensorineural hearing loss present since the age of 20 years and she was myopic. She also had microscopic and intermittent macroscopic haematuria; serum urea and creatinine were normal. The mother had no upper gastrointestinal, respiratory, or genitourinary symptoms. CT scan of the thorax showed no evidence of oesophageal or endobronchial thickening and CT scan of the pelvis and transvaginal ultrasound were normal. She therefore had no evidence of diffuse leiomyomatosis. Peripheral blood smear was normal without evidence of elliptocytosis.

SISTER (II.2)

The 5 year old sister was in excellent general health; her growth and development were normal. She had no facial, audiological, or ophthalmological problems. She did, however, have persistent microscopic haematuria. Peripheral blood smear was unremarkable.

\section{OTHER RELATIVES}

The proband's father had no physical or laboratory abnormalities including no evidence for elliptocytosis on blood smear. The proband's aunt, two uncles, and grandparents on the maternal side reportedly had none of the problems identified in the affected family members.

Results

IMMUNOHISTOCHEMISTRY ESTABLISHES THE DIAGNOSIS OF ALPORT SYNDROME

Following the observation that four family members had some features suggestive of Alport syndrome, a punch skin biopsy was obtained from the proband. No specific immunochemical staining of the epidermal basement membrane was detected with an anti- $\alpha 5$ (IV) chain antibody (fig 4). This finding in the setting of familial haematuria and hearing loss is virtually diagnostic of the $\mathrm{X}$ linked form of Alport syndrome. ${ }^{25}$

MICRODELETION INVOLVING THE COL4A5 GENE PCR analysis of 15 exons randomly interspersed over the COL4A5 gene, including

Table 1 Quantitation of erythrocyte membrane proteins

\begin{tabular}{lcccc}
\hline $\begin{array}{l}\text { Family } \\
\text { member }\end{array}$ & $\begin{array}{l}\text { Spectrin/band3 } \\
\text { ratio }\end{array}$ & $\begin{array}{l}\text { Ankyrin/band3 } \\
\text { ratio }\end{array}$ & $\begin{array}{l}\text { Protein 4.1/band 3 } \\
\text { ratio }\end{array}$ & $\begin{array}{l}\text { Pallidin/band3 } \\
\text { ratio }\end{array}$ \\
\hline I.1 & 95 & 92 & 97 & 95 \\
II.1 & 95 & 100 & 101 & 97 \\
II.2 & 101 & 102 & 108 & 103 \\
II.3 & 104 & 121 & 98 & 98 \\
\hline
\end{tabular}

${ }^{\star}$ Ratios are expressed as percentage of control. exons 1 and 51, generated no products in DNA samples from each brother. The presence of a deletion was confirmed by Southern blotting analysis on DNA samples from both boys by using cDNA probes ${ }^{2126}$ covering the entire COL4A5 gene (see example in fig 5). None of the probes, including JZ4 and PF7 (covering exons 1-9 and exon 51-3' untranslated region, respectively), showed any bands in the patients (not shown). Analysis of the polymorphic marker $2 \mathrm{~B} 6,{ }^{27}$ located just 3 ' to the COL4A5 gene, confirmed that the deletion extends beyond the COL4A5 gene (no PCR product in male patients). Moreover, analysis of this flanking marker, 2B6, showed lack of heterozygosity in both the mother (I.2) and sister (II.2) who carry different alleles, and transmission of only the paternal allele to II.2 (not shown). This result can be explained by the presence of a deletion involving the COL4A5 gene on one of the maternal $\mathrm{X}$ chromosomes and transmission of this $\mathrm{X}$ chromosome to all three of her children. Neither maternal grandparent shows a COL4A5 deletion in DNA extracted from lymphocytes.

\section{UNUSUAL FORM OF APPARENTLY X LINKED} ELLIPTOCYTOSIS

Peripheral blood smears from the proband (II.I) and his brother (II.3) showed distinct elliptocytosis (fig 3); peripheral smears from other family members were unremarkable. Neither boy exhibited anaemia or reticulocytosis. Qualitative and quantitative analysis of red cell membrane proteins by SDS-PAGE on samples from all three sibs and the father were within normal limits (table 1). In addition, no allelic loss at SPTA1 (1q22-23), SPTB (14q23-24), EPB3 (17q12-21), EPB41 (1p33p34.2), or ANK1 (8p11.2) loci was detected by DNA analysis (data not shown).

The mechanical stability and rigidity of erythrocyte membranes were examined using an ektacytometer. Measurements of mechanical stability of membranes derived from erythrocytes of both parents and all three children were normal. Membranes from all five subjects also exhibited normal rigidity. Normal ektacytometry in spite of distinct elliptocytosis on peripheral blood smear is highly unusual and suggests that the boys have a previously unrecognised form of hereditary elliptocytosis.

\section{Discussion}

The association of Alport syndrome with several other additional features has been previously described. None of these reported conditions, however, bears resemblance to the pathology observed in this family. The affected males in this family have typical features of $\mathrm{X}$ linked Alport syndrome (haematuria and hearing loss) but, in addition, display features not at all typical of Alport syndrome, notably mental retardation, facial and digital dysmorphology, and elliptocytosis. Although Alport syndrome has been described in conjunction with mental retardation and macrocephaly in males by Robson $e t a l,{ }^{16}$ the boys in this family have normal head circumferences making it less likely that the same gene is involved in both families. 
However, an X chromosome microdeletion has not been formally excluded in the family described by Robson et al. ${ }^{16}$ The findings in the proband and his brother have some overlap with the FG syndrome. FG syndrome is an X linked mental retardation syndrome with characteristic craniofacial and physical abnormalities. ${ }^{28}$ While there is concordance for a few relatively non-specific features, notably mental retardation, hypotonia, deafness, and fetal pads, the most distinctive facial feature observed in the boys reported in this paper is midface hypoplasia. This finding is not a prominent feature in FG males, who usually manifest a tall, broad forehead, upsweep of the frontal hairline, and megalencephaly. Moreover, the males we describe lack some of the other common features of FG, such as anal anomalies/constipation, broad thumbs and halluces, and failure to thrive. The overlap with FG syndrome is only partial; however, as FG syndrome may be aetiologically heterogeneous, we cannot exclude overlap with a subset of FG cases. The affected males in this family do not resemble any other reported $\mathrm{X}$ linked mental retardation condition. ${ }^{29}{ }^{30}$ Specifically, the constellation of physical findings and medical problems differs from those seen in previously described $\mathrm{X}$ linked mental retardation conditions. Furthermore, several of these conditions have been mapped to regions on the $\mathrm{X}$ chromosome distinct from the COL4A5 locus.

Alport syndrome has been associated with several different haematological abnormalities including macrothrombocytopenia, leucocyte inclusions, and May-Hegglin anomaly. ${ }^{13-15} \mathrm{He}-$ reditary elliptocytosis (HE) has, however, never been associated with Alport syndrome.

The aetiology of $\mathrm{HE}$ in this kindred is unclear. Previously reported genetic defects associated with $\mathrm{HE}$ include abnormalities of alpha spectrin, beta spectrin, protein 4.1 , and glycophorin C. No qualitative or quantitative defects in alpha or beta spectrin or protein 4.1 were detected on one dimensional gel electrophoresis of erythrocyte membrane proteins from affected family members. A glycophorin C abnormality was not specifically excluded; however, glycophorin C deficient elliptocytes (the Leach phenotype) are deficient in protein $4.1^{3132}$ and protein 4.1 deficiency was not found in the erythrocytes of any of the four family members studied.

The apparent $\mathrm{X}$ linked mode of inheritance of the HE in this kindred leads one to consider the possibility of a defective or deficient $\mathrm{X}$ linked erythrocyte membrane protein. $\mathrm{p} 55$, the human homologue of dlg, a Drosophila tumour suppressor gene, is one such protein ${ }^{33}{ }^{34}$ but it has not been associated with HE. It is unlikely that p55 is deleted or disrupted in this family since it is localised to $\mathrm{Xq} 28 .^{35}$ Furthermore, p55 deficient erythrocytes would presumably have abnormal protein 4.1 and glycophorin levels. ${ }^{36}$ In the few cases of elliptocytosis where erythrocyte membrane abnormalities were not detected on one dimensional gels, ektacytometry was diagnostic of an erythrocyte membrane defect. ${ }^{373}$ All five family members had normal ektacytometry results suggesting that the boys have a previously undescribed form of elliptocytosis.

In summary, we report a family displaying features consistent with a new contiguous gene deletion syndrome involving the COL4A5 gene at Xq22. Major clinical findings include $X$ linked Alport syndrome in all gene deletion carriers in addition to mental retardation, elliptocytosis, and midface hypoplasia in the affected males. This constellation of findings should allow straightforward recognition of the condition in other families with affected males. We propose that the additional abnormalities in affected males of this family are attributable to deletion or disruption of $\mathrm{X}$ linked recessive genes adjacent to the COL4A5 gene. Two alternate genetic mechanisms, cosegregation of an autosomal recessive disorder or a noncontiguous $\mathrm{X}$ linked disorder, cannot be formally excluded. They are, however, much less likely explanations for the findings in this family than a contiguous gene deletion syndrome. Work is in progress to characterise the exact extent of the deletion beyond the COL4A5 gene and to clone putative genes associated with $\mathrm{X}$ linked mental retardation, facial morphogenesis, and red cell structure.

This work was supported in part by grants from the National Institutes of Health, the March of Dimes Birth Defects Foundation, and a Telethon Grant to AR (E 536).

1 Kashtan CE, Michael AF. Alport syndrome. Kidney Int 1996;50:1445-63.

2 Barker DF, Hostikka SL, Zhou J, et al. Identification of mutations in the COLAA5 collagen gene in Alpor syndrome. Science 1990;248:1224-7.

3 Mochizuki T, Lemmink HH, Mariyama M, et al. Identification of mutations in the alpha 3(IV) and alpha 4(IV) collagen genes in autosomal recessive Alport syndrome. Nat Genet 1994;8:77-81.

4 Feingold J, Bois E, Chompret A, Broyer M, Gubler MC, Grunfeld JP. Genetic heterogeneity of Alport syndrome. Kidney Int 1985;27:672-7.

5 Renieri A, Bruttini M, Galli L, et al. X-linked Alport syndrome: an SSCP-based mutation survey over all 51 exons of the COLAA5 gene. Am 7 Hum Genet 1996:58: exons of the

6 Knebelmann B, Breillat C, Forestier L, et al. Spectrum of mutations in the COL4A5 collagen gene in X-linked Alport syndrome. Am ₹ Hum Genet 1996;59:1221-32.

7 Antignac C, Knebelmann B, Drouot L, et al. Deletions in the COL4A5 collagen gene in X-linked Alport syndrome. $f$ Clin Invest 1994;93:1195-207.

8 Renieri A, Galli L, Grillo A, et al. Major COL4A5 gene rearrangements in patients with juvenile type Alport syndrome. Am f Med Genet 1995;59:380-5.

9 Zhou J, Mochizuki T, Smeets H, et al. Deletion of the paired alpha 5(IV) and alpha 6(IV) collagen genes in inherited alpha 5(IV) and alpha 6(IV) collagen genes in inth

10 Renieri A, Bassi MT, Galli L, et al. Deletion spanning the $5^{\prime}$ ends of both the COLAA5 and COLAA6 genes in a patient with Alport syndrome and leiomyomatosis. Hum Mut 1994;4:195-8.

11 Heidet L, Dahan K, Zhou J, et al. Deletions of both alpha 5(IV) and alpha 6(IV) collagen genes in Alport syndrome and in Alport syndrome associated with smooth muscle tumours. Hum Mol Genet 1995;4:99-108.

12 Dahan K, Heidet L, Zhou J, et al. Smooth muscle tumors associated with X-linked Alport syndrome: carrier detection in females. Kidney Int 1995;48:1900-6.

13 Epstein CJ, Sahud MA, Piel CF, et al. Hereditary macrothrombocytopathia, nephritis and deafness. Am $\mathcal{F}$ Med 1972;52:299-310.

14 Peterson LC, Rao KV, Crosson JT, White JG. Fechtner syndrome - a variant of Alport's syndrome with leukocyte inclusions and macrothrombocytopenia. Blood 1985;65: inclusions

15 Brivet F, Girot R, Barbanel C, Maier M, Crosnier J. Hereditary nephritis associated with May-Hegglin anomaly. Nephron $1981 ; 29: 59-62$.

16 Robson WLM, Lowry RB, Leung AKC. X-linked recessive nephritis with mental retardation, sensorineural hearing loss, and macrocephaly. Clin Genet 1994;45:314-17.

17 Butkowski RJ, Wieslander J, Kleppel M, Michael AF, Fish AJ. Basement membrane collagen in the kidney: regional localization of novel chains related to collagen IV. Kidney Int 1989;35:1195-202. 
18 Ding J, Kashtan CE, Fan WW, et al. A monoclonal antibody marker for Alport syndrome identifies the Alport antigen as the alpha 5 chain of type IV collagen. Kidney Int 1994;45 1504-6.

19 Kashtan C, Fish AJ, Kleppel M, Yoshioka K, Michael AF Nephritogenic antigen determinants in epidermal and rephritogenic antigen determinants in epidermal and renal basement membranes of kindreds with Alpo

20 Cheong HI, Kashtan CE, Kim Y, Kleppel MM, Michael AF. Immunohistologic studies of type IV collagen in anterior lens capsules of patients with Alport syndrome. Lab Invest 1994;70:553-7.

21 Myers JC, Jones TA, Pohjolainen ER, et al. Molecular cloning of the $\alpha 5$ (IV) collagen and assignment of the gene to the region of the $\mathrm{X}$ chromosome containing the Alport syndrome locus. Am F Hum Genet 1990;46:1024-33.

22 Johnson RM. The kinetics of resealing of washed erythrocyte ghosts. F Membr Biol 1975;22:231-53.

23 Mohandas N, Clark MR, Health BP, et al. A technique to detect reduced mechanical stability of red cell membranes: relevance to elliptocytic disorders. Blood 1982; 59:768-74

24 Marchesi SL, Knowles WJ, Morrow JS, Bologna M, Marchesi VT. Abnormal spectrin in hereditary elliptocytosis. Blood 1986;67:141-51.

25 Yoshioka K, Hino S, Takemura T, et al. Type IV collagen alpha 5 chain. Normal distribution and abnormalities in $\mathrm{X}$-linked Alport syndrome revealed by monoclonal antibody. Am F Pathol 1994;144:986-96.

26 Zhou J, Herz JM, Leinonen A, Tryggvason K. Complete amino acid sequence of the human $\alpha 5$ (IV) collagen chain and identification of a single-base mutation in exon 23 converting glycine 521 in the collagenous domain to cysteine in an Alport syndrome patient. $\mathcal{F}$ Biol Chem 1992; 267:12475-81.

27 Barker D, Cleverly J, Fain PR Two CA-dinucleotide polymorphisms at the COL 4A5 (Alport syndrome) gene in Xq22. Nucleic Acids Res 1992; 20:929.

28 Thompson E, Baraitser M. FG syndrome. 7 Med Genet 1987;24:139-43.
29 Lubs HA, Chiurazzi P, Arena JF, Schwartz C, Tranebjaerg L, Neri G. XIMR genes: update 1996. Am ₹ Med Genet 1996;64:147-57.

30 Gedeon AK, Donnelly AJ, Mulley JC, Kerr B, Turner G. How many X-linked genes for non-specific mental retardation (MRX) are there? Am f Med Genet 1996;64:158-62.

31 Telen MJ, Le Van Kim C, Chung A, Cartron JP, Colin Y. Molecular basis for elliptocytosis associated with glycophorin C and D deficiency in the Leach phenotype. Blood orin C and D defin

32 Nash GB, Parmar J, Reid ME. Effects of deficiencies of glycophorins $\mathrm{C}$ and $\mathrm{D}$ on the physical properties of the red cell. Br f Haematol 1990;76:282-7.

33 Bryant PJ, Woods DF. A major palmitoylated membrane protein of human erythrocytes shows homology to yeast guanylate kinase and to the product of a Drosophila tumor suppressor gene. Cell 1992;68:621-2.

34 Ruff P, Speicher DW, Husain-Chishti A. Molecular identification of a major palmitoylated erythrocyte membrane protein containing the src homology 3 motif. Proc Natl Acad Sci USA 1991;88:6595-9.

35 Metzenberg AB, Gitschier J. The gene encoding the palmitoylated erythrocyte membrane protein, $\mathrm{p} 55$, originates at the $\mathrm{CpG}$ island $3^{\prime}$ to the factor VIII gene. Hum Mol Genet 1992;1:97-101.

36 Alloisio N, Dalla Venezia N, Rana A, et al. Evidence that red blood cell protein p55 may participate in the skeletonmembrane linkage that involves protein 4.1 and glycophorin C. Blood 1993;82:1323-7.

37 Gallagher PG, Weed SA, Tse WT, et al. Recurrent fatal hydrops fetalis associated with a nucleotide substitution in the erythrocyte beta-spectrin gene. F Clin Invest 1995; 95:1174-82.

38 Gallagher PG. Mutation of a highly conserved residue of $\beta-I$ spectrin associated with fatal and near-fatal neonatal hemolytic anemia. $\mathcal{F}$ Clin Invest 1997;99:267-77. 